\title{
A Systematic Review of Public Attitudes, Perceptions and Behaviours Towards Production Diseases Associated with Farm Animal Welfare
}

\author{
Beth Clark $^{1}$ - Gavin B. Stewart ${ }^{1}$ Luca A. Panzone ${ }^{1}$. \\ I. Kyriazakis ${ }^{1} \cdot$ Lynn J. Frewer $^{1}$
}

Accepted: 11 April 2016/Published online: 27 April 2016

(C) The Author(s) 2016. This article is published with open access at Springerlink.com

\begin{abstract}
Increased productivity may have negative impacts on farm animal welfare (FAW) in modern animal production systems. Efficiency gains in production are primarily thought to be due to the intensification of production, and this has been associated with an increased incidence of production diseases, which can negatively impact upon FAW. While there is a considerable body of research into consumer attitudes towards FAW, the extent to which this relates specifically to a reduction in production diseases in intensive systems, and whether the increased incidence of diseases represents a barrier to consumer acceptance of their increased use, requires further investigation. Therefore a systematic review of public attitudes towards FAW was conducted, with a specific focus on production diseases in intensive systems. Four databases were searched to identify relevant studies. A screening process, using a set of pre-determined inclusion criteria, identified 80 studies, with the strength of evidence and uncertainty assessed for each. A thematic analysis led to the identification of 6 overarching themes constructed from 15 subthemes. The results demonstrate that the public are concerned about FAW in modern production systems. Concern varied in relation to age, gender, education and familiarity with farming. Naturalness and humane treatment were central to what was considered good welfare. An evidence gap was highlighted in relation to attitudes towards specific production diseases, with no studies specifically addressing this. However, the prophylactic use of antibiotics was identified as a concern. A number of dissonance strategies were adopted by consumers to enable guilt free meat consumption.
\end{abstract}

Lynn J. Frewer

lynn.frewer@newcastle.ac.uk

1 School of Agriculture Food and Rural Development, Agriculture Building,

Newcastle upon Tyne NE1 7RU, UK 
Keywords Farm animal welfare $\cdot$ Public attitudes $\cdot$ Food consumption $\cdot$ Production diseases

\section{Introduction}

Conflicts may arise between the drive to increase productivity in animal production systems, and farm animal welfare (FAW; Austin et al. 2005). More efficiency within production systems is required to meet growing demand for animal products (Godfray and Garnett 2014). At the same time, production systems are becoming a focus of increased public scrutiny as a result of increasing ethical concerns surrounding farming methods (European Commission 2007). Despite their concern, the public may have very little or no understanding of modern farming practices and their impact on productivity and welfare (Harper and Henson 2001). The incidence of production diseases can increase in intensive systems, and can negatively affect FAW (Bengtsson and Greko 2014). The public represent an important user of the food-chain, and can drive demand for specific food products (Jensen 2006). Their views, concerns and preferences must be taken into consideration concerning the implementation and monitoring of animal production systems, so that effective and acceptable regulations can be designed and enforced (Bennett et al. 2002).

Given the subjectivity of FAW assessment a combination of both legislative and market-based options would appear to offer the most viable solution for meeting public expectations, with the latter offering those with the highest concern a means to express their preferences above the minimum legislative standards implemented. There is also evidence to suggest an increasing ambivalence towards modern farming by consumers (Boogaard et al. 2006), and increased disassociation between production and consumption in terms of consumer attitudes (Harper and Henson 2001). Many consumers appear appreciative of the quality and safety guaranteed by these systems, yet express concerns in relation to the management practices and associated standards used (Boogaard et al. 2011). It would also appear that concerns associated with FAW and production do not correspond to purchase and consumption practices, with sales of welfare friendly products (WFP) much lower than the reported levels of concern (European Commission 2007). This indicates a potential discrepancy between an individual's role as a citizen and as a consumer (Boogaard et al. 2011; Grunert 2006), with citizens and consumers having different concerns in different contexts. As a result, FAW may not be considered by all consumers whilst shopping. This citizen-consumer duality may partly explain the weak link often observed between attitudes and behaviour (Te Velde et al. 2002). It also explains why non-consumers are vocal in their opinions of FAW and look to legislation, government and other stakeholders to improve standards (Kjærnes et al. 2007).

Previous research has demonstrated that some consumers are willing-to-pay (WTP) for a range of products that exceed minimum welfare standards (Lagerkvist and Hess 2011), indicating niche markets for WFP (Wathes et al. 2013) and that market-based solutions role in maintaining welfare standards. Heterogeneity within the WTP literature has been explored in previous reviews in relation to consumer 
characteristics, different welfare aspects and animal types (Lagerkvist and Hess 2011). However, additional underlying variables that could further explain differences in behavioural intention have been neglected, and there has been no previous comprehensive exploration of these variables in relation to attitudes. As FAW is essentially subjective (Bennett and Blaney 2003), it is important to gain an understanding of the underpinning ethical assumptions (Lassen et al. 2006), including the moral, cultural or sociological reasons that form the basis of public concern. This facilitates understanding of citizen and consumer behaviour.

This review seeks to establish (1) the public's attitudes towards FAW; and (2) what are the public's attitudes towards interventions to reduce production diseases. Heterogeneity within the data will be explored in relation to a number of secondary objectives, specifically to determine whether; (3) socio-demographic factors affect attitudes and beliefs in relation to FAW; (4) socio-economic factors affect attitudes and beliefs in relation to FAW; (5) different aspects of welfare affect attitudes and beliefs in relation to FAW, and (6) citizens more concerned than consumers in relation to FAW.

\section{Methods}

\section{Literature Search}

A protocol for the review was published online prior to its commencement to provide transparency and to enable feedback from other researchers (Clark et al. 2014). Four different databases were searched; Scopus, ISI Web of Knowledge, AgEcon Search and Google Scholar, with the latter 2 enabling the identification of relevant grey literature. Databases were searched using a combination of different search terms, with combinations specific to each database. Only studies from the past 20 years (1995 onwards) were included. Search strings were trialled and refined in a multistep process, with the face validity of each search addressed by checking search results for key authors identified through an initial search. Animal specific search terms were not used as they frequently returned studies that originated in the natural rather than the social sciences. A copy of the trial and final search terms can be obtained by contacting the corresponding author. Key authors in the field were also contacted for additional sources of grey literature or any unpublished works. Returned studies were exported into an Endnote library, and duplicates were removed. Studies were then excluded in a two stage sifting process in relation to a set of predetermined inclusion criteria as described below. Reference lists of included studies were screened to identify any further relevant studies.

Qualitative and quantitative studies which measured consumer attitudes, preferences, perceptions, beliefs and perceived ethical obligation towards products produced to a specified FAW standard were included. All studies included sampled members of the general public. All farm animal types, animal based products and aspects of welfare were considered eligible for inclusion, with welfare measures being those described to participants as altering the lives in animals in some way, either specifically (e.g. tail docking) or more generally, (e.g. use of outdoor 
production systems). Welfare measures in relation to production diseases targeted the reduction or control of diseases. Antibiotic use was considered as a proxy for interventions to reduce production diseases (Hughes and Heritage 2002), rather than as a growth promoter unless specifically specified. Only studies which were written in English were included. If two or more studies reported duplicate populations the study presenting the most information for analysis was retained. Duplicate studies were not coded, but were checked to ensure that no extra details or covariates were missed and that their findings concurred with results of the review. References to studies included in the review and those excluded at the full text stage can be obtained by contacting the corresponding author.

\section{Data Extraction and Analysis}

As quantitative and qualitative data were included in the analysis, and a large variety of measures and scales were used to measure consumer attitudes, metaanalysis was not possible. Therefore a narrative analysis was conducted following the Economic and Social Research Council (ESRC) narrative synthesis guidelines (Popay et al. 2006). Papers included were first read and a summary table created to provide an overview of the different studies. This provided a mechanism for the researcher to become familiar with the data before coding, and provided an initial idea of the codes and subsequent themes. This formed the basis of the thematic coding approach taken (Thomas and Harden 2008; Braun and Clarke 2006). Data was then analysed using QSR Nvivo 10. A computer based coding approach was used due to the large number of studies included in the analysis. The researcher retained an active role in making conceptual and interpretative decisions in relation to the data analysis (Weitzman 2000).

Coding of the papers deviates from that stated in the protocol (Clark et al. 2014), with the qualitative and quantitative data being analysed in a single, as opposed to separate streams. The theory of planned behaviour (TPB) was not used in analysis, due to the returned data not fitting within the framework, with the free-coding retaining much more information from the data. Free-coding also enabled a data driven approach and greater researcher reflexivity. Although some individual studies did demonstrate elements of the TPB, these specifically incorporated the TPB into their methodologies. It is also important to note that the TPB has recently received criticism (Sniehotta et al. 2014), and therefore may not be the most appropriate framework to use in the context of FAW, as it appears to miss some of the nuances associated with this topic. Deviating from the protocol may induce bias into the review. However this is unlikely due to the comprehensiveness of the search terms used, and the nature and level of transparency in the analysis, resulting in maximum data inclusion.

Following the primary researcher familiarising themselves with the studies in the data base, open-coding was initially used to extract data from studies, with codes also being generated in relation to all objectives mentioned in "introduction" section. The initial coding framework was then refined after half of the studies were coded to provide a more representative framework. This involved rearranging different codes or breaking them down into multiple separate codes to create more 
detail. Codes were renamed to make them more informative and reflective of the content they included. The remaining studies were then coded based on the new framework. These final codes were then grouped into themes (Table 1), based on the primary researchers' conceptual insight, and were discussed and refined with the rest of the research team.

\section{Critical Appraisal}

Studies were critically appraised to assess bias and validity. A critical appraisal document was developed to enable appraisal of the diverse nature of studies included in the review. A separate tool was developed for qualitative and quantitative studies due to the inherent differences in the nature of the methods (Bryman 2012). The tool was developed by consulting a number of existing guidelines and recommendations and provided a document relevant to a nonhealthcare context. The tool considered construct validity, internal and external validity, and the reliability of the studies included in the analysis (Yin 2009) in the form of 7 different criteria commonly used to assess study quality; study aims, study design, recruitment of participants, data collection, data analysis, ethical considerations of the study and the discussion of findings, with the role of the researcher in relation to data collection and analysis being assessed in qualitative studies providing an eighth category. Each category was assigned a risk of bias score based in a 5 point scale, ranging from very high to very low according to the criteria in each section. The overall study quality was then judged based on the quality of each of the criteria. For mixed methods studies, critical appraisal was conducted for each separate method.

Table 1 A summary of themes from included studies $(\mathrm{n}=80)$

\begin{tabular}{ll}
\hline Theme & Subtheme \\
\hline Concept of welfare & $\begin{array}{l}\text { Definition welfare } \\
\text { Naturalness } \\
\text { Humane treatment (inc. production } \\
\text { diseases) }\end{array}$ \\
& Overall \\
Attitudes towards welfare & Animal type \\
& Population characteristics \\
& Citizens versus consumer role \\
Role and orientation & Anthropocentric versus zooncentric \\
& concerns \\
Behaviour & Consumption patterns \\
Barriers and facilitators & Willingness to pay \\
& Barriers to consumption \\
Mediators & Facilitators of consumption \\
& Trust \\
& Responsibility \\
& Knowledge \\
\hline & \\
&
\end{tabular}


No studies were excluded based on the critical appraisal, with the findings being taken into account during the analysis when assessing the overall strength of evidence as part the GRADE (Grading of Recommendations, Assessment, Development and Evaluation) analysis (Meader et al. 2014). The GRADE framework was also used to provide an overview of the strength of evidence and was again adapted to enable the inclusion of qualitative research (Stewart et al. 2015). An overall assessment based on the results of each of the 5 was then made.

- Risk of bias addressed through critical appraisal of each study using the risk of bias tool, and was graded as a high, moderate or low risk of bias.

- Inconsistency traditionally done though forest plots and $\mathrm{I}^{2}$ values. This was evaluated from the summary of evidence table for overall variation, and during data analysis to establish how much variation there was in each theme. This was assessed as high, moderate, or low, with a higher risk of bias associated with a higher variation.

- Indirectness was established by examining whether studies were focused on addressing the PICO elements of the research question, such as whether the population were members of the public and whether FAW was the sole focus of the research. This was assessed as high, moderate or low.

- Imprecision due to the qualitative nature of the analysis $95 \%$ confidence intervals were not available. Therefore this was determined from a number of factors. For qualitative studies, this included examination of how confident the authors were of their findings and also assessing study generalizability. For quantitative studies, this was assessed through examining the generalizability of the findings, whether any potential confounding factors were explicitly mentioned and the sample size. Precision was assessed as high, moderate or low.

- Publication bias this is traditionally assessed through funnel plots but due to the thematic analysis used this was not possible. Differences in outcomes between published and unpublished studies were therefore examined, and the risk of bias assessed as either strongly suspected or undetected depending on whether differences were present or not.

A summary of these findings along with all supporting documents, including the critical appraisal tools and results, can be obtained by contacting the corresponding author.

\section{Results}

\section{Overview}

80 studies were included for analysis and the majority of studies included were quantitative $(\mathrm{n}=62)$. Of these, 43 were surveys, 17 were WTP studies, 1 was based on modelling existing data and another was an information display matrix. Of the 9 qualitative studies there were 4 focus groups, 4 interviews and 1 citizen's panel. The remaining 9 studies applied mixed methods, with 5 containing both qualitative and 
quantitative methods, 3 containing multiple qualitative methods and 1 containing multiple quantitative methods.

The majority of studies were conducted in Europe $(n=59)$, with Northern and Western European countries most commonly represented. Of the remaining studies, 14 were conducted in North America, 2 in South America, 2 in Australasia, 2 in Asia, 1 in Africa, and 1 in multiple regions. Nearly half of studies $(n=33)$ did not focus on specific animal types. Of those that did, pigs were most commonly included $(n=17)$, followed by multiple named animal types $(n=8)$, broiler chickens $(n=8)$, and layer hens $(n=6)$, with fish, lamb, beef and dairy cows being the only other animal types studied.

The majority of studies were peer reviewed journal articles $(n=65)$. The remaining 15 were conference papers, project reports, theses and working papers. Critical appraisal revealed that studies were of mixed quality and therefore a mixed risk of bias. Generally, quantitative studies were rated as less risk of bias than qualitative studies, with only 1 qualitative study having low risk of bias. All qualitative studies had an appropriate research design and presented and discussed the results adequately. The majority of studies also had a clear statement of aims. Information regarding participant recruitment, and how data was collected and analysed was not always as clear or indeed reported. Justification of the sample size, whether the data collection addressed the research issue, whether data analysis was sufficiently rigorous and acknowledgment of limitations were generally least frequently or badly reported. No qualitative studies discussed obtaining ethical approval or the role of the researcher in data collection or analysis.

Most of the quantitative studies provided clear statements of study aims. When this was not the case it was due to population, intervention, control, outcome (PICO) elements being unclear. Most quantitative studies had an appropriate research design, although few provided a justification of the methods used. Details surrounding participant recruitment were unclear, in particular in relation to the justification of the sample size and reporting the response rate. The majority of studies provided sufficient information concerning data collection, analysis and reporting of findings. However, information regarding the reliability and validity of the instrument, prevention of selective use of data and study limitations were less frequently reported. Findings were not always adequately discussed, or discussed in relation to the original research aims and objectives. Again ethical considerations associated with the study design were rarely considered, being mentioned in 9 of the 62 studies. Risk of bias and reporting standards for mixed methods studies were much the same as for the qualitative and quantitative studies. Data analysis and the discussion of findings were assigned a higher risk of bias, mostly for the qualitative studies. This could be due to space limitations of journals, resulting in insufficient space for enough detail about multiple methods.

The GRADE assessment indicated a moderate strength of evidence, suggesting that results of the review should be interpreted with caution. Publication bias was not detected, as there appeared to be no differences in results between peer reviewed and non-peer reviewed studies. Indirectness was low, with the majority of studies involving the public and designed specifically to examine perceptions of, and attitudes towards FAW. Imprecision was high, with few studies acknowledging 
cofounding factors which may influence their results in particular. Finally, there was a moderate risk of bias as a result of inconsistency across some themes, but consistent findings across others.

Table 1 provides an overview of the themes included in the review, and the subthemes they were derived from.

\section{Concept of Welfare}

\section{Definition of Welfare}

Although what was thought to constitute as good FAW varied, humane treatment and naturalness were central to acceptability. There was also a growing recognition of FAW beyond health and housing, taking into account 'off the farm aspects' such as transport and slaughter, and the psychological aspects of welfare including the animals' natural behaviours and instincts, with the latter being more of a moral consideration and so more contested by the public. This suggests that both consumers and citizens utilise a holistic view of welfare and health, although these may not always be equal in terms of the weight given to each. Study participants acknowledged that what was bad for the animals was ultimately bad for consumers, particularly in relation to the control of disease, and consumer negativity regarding the use of antibiotics in intensive production systems, with all being linked to human health concerns. In relation to health and treatment, there was evidence that both consumers and citizens acknowledge that antibiotic use cannot totally be avoided, with concerns primarily relating to their overuse.

\section{Naturalness}

Naturalness was central to attitudes and concerns in relation to both the animals' behaviours and living conditions. It was thought to be important for both animal physical and psychological wellbeing, with the hampering of natural behaviours being seen as having a negative impact on the animals' overall health. Naturalness was defined as providing enough space and associated freedom to allow the animals to behave according to their natural instincts, and also included having access outdoors and to un-adulterated feed. Modern, intensive production systems were therefore typically viewed as unnatural as they breached one or more of these criteria. Conversely, more traditional, extensive and outdoor systems were viewed as more natural and as producing higher quality products. Despite overriding preferences for naturalness, there was some appreciation of certain benefits associated with modern production systems such as improved hygiene.

\section{Humane Treatment}

Perceptions and attitudes of study participants indicated that the animals' health and basic physiological needs were linked to various factors including access to natural light, cleanliness and sufficient space (avoidance of overcrowding). Unsurprisingly, considering how central naturalness was in determining welfare, efforts to protect 
health at the expense of naturalness were not supported. Linked to this was the control and absence of disease. No studies focused specifically on production diseases, although the results of 21 studies included reference to antibiotic use. Concerns surrounding disease were linked to cramped conditions leading to higher disease prevalence, and the preventative and overuse of antibiotics. Treatment of disease and injury was important, and the use of antibiotics in this context was considered acceptable. Addition of antibiotics to animal feed was viewed as unnatural and inappropriate, along with other additives such as growth hormones. Feed in general was considered an important element of animal nutrition and health.

Together with animal feed, 'on the farm', housing conditions were the most frequently studied and discussed aspect of welfare. These were most commonly discussed in relation to the amount of space animals had, the cleanliness of the housing conditions, and the naturalness of the environment, for example, whether animals had outdoor access. Access to sufficient food and water was also considered important. Intensive systems, such as barns, were considered too cramped. Outdoor access and lower stocking densities were preferred. Study participants tended to express the view that alternatives to current practices were needed, in particular in relation to the use of battery cages in poultry, gestation crates and castration without anaesthetic in pigs, which were considered inhumane. Good husbandry practices were also mentioned with concerns raised in relation to neglect and mistreatment. Good husbandry was thought to include regular animal contact and careful handling, and it was recognised that this is more difficult in the industrialised context modern farming occupies.

Concerns over animal transport and slaughter conditions were raised (and often associated). Slaughter conditions were deemed important, primarily in relation to ensuring a quick and pain-free death to minimise suffering. Conditions during transport, such as access to food and water and the length of transportation were also thought important, and study participants indicated that the duration needed to be as short as possible. Both of these factors varied in importance. Concerns were not always raised spontaneously during qualitative studies.

The consideration of psychological wellbeing of animals was thought to represent an important part of humane treatment, although there were more diverse views on this. The majority believed that animals had the capability to suffer psychologically and emotionally. The animals' integrity and ability to express natural behaviours was perceived as an essential part of achieving psychological wellbeing, which was central to animals being able to live a natural life. This was also associated with housing conditions, especially animals' ability to interact with other animals, space restrictions and freedom to move around housing areas.

\section{Attitudes Towards Welfare}

\section{Overall}

Although positive and negative attitudes towards modern farming systems were identified, in general study participants were concerned about current FAW standards. Participants viewed modern production systems as' bad, cruel, and 
unnatural', which generated a high level of concern. Industrial efficiency was viewed negatively and invariably led to more traditional, smaller and lower intensity farms being preferred. In quantitative studies, the majority of participants reported being concerned about FAW, with the proportion ranging between 46 and $86 \%$ (McKendree et al. 2014; Bennett and Blaney 2003), more commonly towards the higher end of this range. Those who viewed contemporary farming practices more positively were more appreciative of modern production, with benefits like more sanitary conditions, greater efficiency and improved welfare cited. However, these attitudes were normally associated with concerns in relation to the contemporary practices, with increased efficiency and productivity believed to occur at the expense of welfare.

Although negative attitudes toward modern production were raised in general, the level of negativity varied between animal types. Layer hens and broiler chickens were generally viewed as farmed in the worst conditions in relation to FAW, and conditions for dairy cows were generally viewed more positively. Farming conditions for pigs varied across studies, and were generally considered to need less improvement compared to chickens.

\section{Socio-Demographic Characteristics}

Attitudes and concern towards FAW appeared to vary in relation to a number of socio-demographic characteristics, such as age, gender, education, income and whether individuals lived in a rural location. The importance of welfare tended to decrease with age, with younger participants being more likely to have greater awareness of welfare issues, be less convinced about the FAW and have more animal, as opposed to human centred attitudes. Older respondents had more negative attitudes regarding the acceptability of FAW practices or were more accepting of current standards in some studies. Women were generally more concerned, and had more negative views towards modern farming. Segmentation analysis across studies frequently indicated a higher proportion of women in the "more concerned" or "welfare conscious" groups.

Those with a higher education were likely to be more aware of FAW and tended to be more concerned about modern farming conditions, as well as reporting greater familiarity with farming practices and a greater number of farm visits, although this was only investigated in a few studies. Greater concern was reported by those with both lower and higher incomes. Those in professional positions demonstrated greater concern although this was thought to be related to participants' higher levels of self-reported knowledge and greater education.

Welfare issues were reported as being more important for those living in urban areas, although rural respondents also reported concerns. Knowledge of FAW was greater for those living in rural locations, and having some connection to agriculture. Living in a rural location was associated with less concern about FAW and being more accepting of modern farming.

A number of other characteristics were investigated less frequently across studies. Pet ownership was linked to more negative views of modern farming, greater concern for FAW, and was motivated by more ethical, (as opposed to human 
health) concerns. Religious and political beliefs were also associated with varying degrees of concern for FAW, with evangelicalism, more frequent church attendance and a stronger religiosity associated with less FAW concern. Those left and centre of the political spectrum were likely to have greater concern compared to those on the right. The trend for households with children was mixed, with evidence for both greater and reduced concern for FAW. Finally vegetarians were much more critical of welfare practices, voiced greater concern about FAW compared to meat eaters, and were more homogenous in their responses.

\section{Role and Orientation}

\section{Consumer Versus Citizens Role}

Consumers and citizens voiced FAW concerns. An individuals' role as a consumer was associated with guilt, with one participant following a farm visit stating "Is this the price to pay for having meat as cheap as possible" (Boogaard et al. 2011). The need for a clear conscience was also expressed, and aside from purchasing WFP, a number of coping strategies were identified to enable guilt-free consumption. Disconnecting the product from the animal it originated from was one strategy, meaning consumers did not have to think about the production processes involved. Another dissociation strategy was convincing themselves that the control of welfare is out of their hands, thereby removing their responsibility. Some consumers also mentioned they would rather not think about certain aspects of production, including those portrayed in the media, and some consumers simply did not want to know from where their meat came.

\section{Anthropocentric Versus Zoocentric Concerns}

Negative attitudes and associated FAW concerns were motivated by either zoocentric (animal) or anthropocentric (human) concerns. A concerned group of individuals, including consumers, exist who tend to view welfare issues from an animal perspective, believing that animals have emotions and can feel pain, with intensive production systems therefore evoking feelings of guilt. They perceive animals to possess more than a utilitarian value to humans and believe the quality of the animals' lives to be important.

Conversely, some individuals' FAW concerns were motivated by their own wellbeing. They seemed to lack an affinity with animals, viewing them as inferior to humans, and having a lower sentience. Although they acknowledged that modern production systems are inhumane, and that they were likely to be causing cruelty by eating meat, they questioned the use of anthropomorphism when discussing welfare. When discussing intensive systems, it was mentioned that "they won't know any different" (Schröder and McEachern 2004) and it "is a (human) right to eat animals" (Harper and Henson 2001), which aside from offering a human centred view may also offer another form of dissonance, by viewing animals as objects rather than sentient beings. This human centred approach is also observable in the additional consumer benefits associated with higher welfare systems (see facilitators 
of consumption). When discussing specific aspects of FAW these often had a human motivation, such as the reduction of the risk of disease transfer and veterinary residues.

\section{Behaviour}

14-51\% of study participants reported intending to, or already having, decreased their consumption of animal products (McKendree et al. 2014; Ellis et al. 2009). The restriction of certain meat types were more common than others, with pork and beef consumption most likely to decrease, and chicken consumption most likely to increase, although this may well be due to health and safety concerns, not just welfare considerations. Pro-welfare behaviour and the level of concern associated with animal production were also associated with consumption practices, with those with greater concern consuming animal products less frequently, purchasing WFP more frequently, and indicating a greater use of welfare related labels. This shows a higher level of involvement is associated with greater levels of pro-welfare behaviour.

Welfare as a motivator for purchase was strongest in women, which is unsurprising considering the greater concern they have surrounding animal production. In terms of the type of WFP consumed, free-range eggs were most frequently purchased and were commonly purchased by those with varying levels of concern. The association between changing consumption practices and sociodemographic characteristics was less apparent, although $\mathrm{ABC} 1$ consumers were more likely to consume WFP, with a higher income associated with an increased WTP, decreased price sensitivity or no difference in consumption. It would also seem that younger individuals were more likely not to eat meat due to ethical, rather than health concerns.

\section{Barriers to, and Facilitators of, Consumption}

\section{Barriers to Consumption}

The majority of participants agreed FAW was important, with those rating it more highly most likely to say that improvements are needed. However, the rated importance of FAW did not always translate into purchasing behaviour. In some focus group discussions, FAW was not mentioned when food attributes were initially discussed, with a number of other attributes assigned a greater importance when purchasing animal products, with most purchase decisions normally involving the evaluation of multiple attributes. Prioritised attributes included quality, freshness, origin, sensory characteristics such as taste, value for money, food safety and human health.

Many consumers believed the availability of WFP to be limited, and that it was too time consuming to locate them. The lack of availability prevents those who are concerned from purchasing their preferred products, resulting in them buying lower welfare alternatives, and the frustration caused by this was apparent. Concerns were also raised over contexts where individuals have little control, such as in restaurants. 
Cost was also as a barrier, with WFP perceived as too expensive to purchase, especially in large quantities, with price premiums thought to take away consumer responsibility for FAW. Welfare was also described as being out of consumer control.

Despite wanting assurances and guarantees about WFP, and citing the availability and ease of identification as barriers to purchase, labels to indicate WFP were not universally supported. Those critical of labels claimed they presented an information overload. Doubts were also raised as to their credibility and reliability, with only $34 \%$ of participants in one study reporting being somewhat trusting of information presented (Makdisi and Marggraf 2011). Labels were also viewed as confusing, especially in terms of being able to identify farming systems. Lack of available information appears more of a problem for those actively trying to seek it. However, consumers indicated that labels could play a positive role in communication and are an opportunity that needs improving. Labelling was identified as the preferred method for the identification of WFP in manty studies, providing additional reassurance to consumers about FAW standards. In relation to existing labelling schemes, women, those with higher education and those in the Scandinavian countries appear best at understanding existing labels, and this corresponds to the greater FAW concern and knowledge in these groups.

\section{Facilitators of Consumption}

WFP were repeatedly associated with, and used as, an indicator of other product attributes, especially quality and additional consumer benefits such as safety, resulting in products having value beyond that of better FAW. Consumers who associated higher welfare with these additional attributes were also WTP more for FAW.

Human health and safety were commonly mentioned benefits of higher welfare systems, with the two likely to be linked. 50-78\% of respondents thought that WFP were healthier (Bennett et al. 2012; Moran and McVittie 2008). In relation to product safety, improved living conditions and the reduced use of antibiotics were thought to contribute to this. Both overall and sensory quality, such as taste, were associated with improved FAW, with more involved consumers more convinced of this relationship. Questions were raised as to the quality of meat originating from intensive production systems and WFP were seen as a means of guaranteeing superior quality products. WFP were also associated with organic production, which evoked less welfare concerns than more intensive systems. More FAW orientated systems were believed to have less of an environmental impact for a number of reasons including; reduced use of chemicals, greater sustainability and protection of the soil, water and air.

\section{Mediators}

\section{Trust and Responsibility}

Trust was an important factor, raised in relation to labelling and those who bear responsibility for ensuring acceptable welfare standards. Implementing a credible inspection system was an important component in establishing and maintaining 
acceptable welfare standards. This entailed ensuring independent bodies were used for accreditation, which would also provide a basis for labelling schemes to avoid the current scepticism surrounding existing labels.

The amount of trust conferred on different stakeholders varied along the foodchain, with actors such as retailers generally less trusted than farmers, although the perceived trustworthiness of farmers and also the government differed between countries, with consumers in Northern European countries trusting these stakeholders more than consumers in Southern Europe. If organisations were perceived as more knowledgeable about, and not engaged in, animal production, they were more trusted.

Responsibility for ensuring acceptable FAW standards was not thought to lie with one actor. The most trusted stakeholders and the stakeholders perceived to be the most responsible were not always the same. Some consumers thought responsibility had been removed from them by the government, or due to increased prices making WFP unaffordable and frequently ranked themselves as amongst the least responsible. Some acknowledged their responsibility, believing society to be the start of a chain of influence of concern. However, they felt powerless to do anything about this as they had no direct involvement with the implementation of FAW.

Welfare was viewed as a government issue, as they can implement regulations and legislation to improve and monitor welfare standards. This was better recognised amongst more educated individuals. The government was perceived as a neutral source as opposed to other stakeholders, such as animal welfare organisations. Respondents in most countries acknowledged the need for improved legislation in their own countries. In China where FAW was an unfamiliar concept, there was recognition that more regulation is needed.

Responsibility was also assigned to stakeholders, such as animal rights organisations, vets, farmers and retailers, with the latter believed to have a need to ensure that animal products are produced responsibly. Consumer views towards farmers varied, with some sympathetic towards them, stating that they need to make a living, with some studies mentioning the need compensation for those who adopt higher welfare standards. Others viewed them as just out to make a profit with economic considerations inevitably overriding public opinion, and focusing on efficiency instead of welfare. They were often viewed as being most responsible, and when greater trust in them was displayed, FAW concerns were reduced.

\section{Knowledge and Sources of Information}

Public concern, and general negative attitudes towards modern production, were underpinned by a lack of knowledge. A general lack of familiarity with modern farming conditions and practices was apparent, especially of 'off the farm' issues. When asked to rate their current knowledge about farming practices, the majority reported that this was low, ranging from $50 \%$ indicating that they are not informed about the subject (Ellis et al. 2009), to $80 \%$ agreeing that they do not possess a lot of knowledge about FAW (Lu 2013). These figures are likely to be higher, as when objective knowledge was measured, correct responses were much lower than the 
corresponding self-reported knowledge values. Evidence of misconceptions was common, especially in relation to what normal farming practices were. Those from Scandinavian countries and those who have visited a farm previously appear to have most knowledgeable about FAW.

There was a desire to be better informed and it was thought that there is currently not enough FAW information available. The evidence suggests that those who describe themselves as having some knowledge are more likely to want to know more, although this finding was not consistent across studies. Numerous sources of FAW information were mentioned, including first-hand personal experience, the government, specific welfare organisations and the media, with the latter the predominant news source. Despite being the most frequently consulted source of information, there were mixed feelings as to how credible it was. Television was the most frequent media channel used, followed by the internet which was increasingly preferred in the more recent studies. Not having an information source was also common, as was being unable to recall seeing any FAW information in in the news recently. One study reported that those who were more concerned about welfare reported seeing more stories relating to it. Overall, greater knowledge was associated with more concern and a greater WTP.

\section{Discussion}

\section{Public Attitudes Towards Farm Animal Welfare}

This review identifies and explores public attitudes towards FAW. 80 studies were identified through a 2 stage search process, and a thematic analysis led to the identification of 6 themes, constructed from 15 subthemes. The results indicate that the public are concerned about FAW, with the majority having a negative attitude towards modern farming. These concerns were related to two main concepts; humane treatment and naturalness, and violation of these was associated with more negative attitudes.

Critical assessment indicated that studies were of a mixed risk of bias, with quantitative studies at a lower risk than qualitative studies. The GRADE assessment indicated a moderate overall strength of evidence, meaning that results of the review should be interpreted with some caution. As the methodological aspects of studies, such as participant recruitment, study design and data analysis, were often rated as a higher risk of bias, future studies could improve the existing body of evidence by including as much methodological information as possible. Only nine individual and eight mixed methods studies involved qualitative research. Although these generally had a higher risk of bias they were some of the most insightful studies and provided a number of insights as to the underlying reasoning behind attitudes and concerns. It would therefore be worthwhile conducting more of these studies to understand particular population groups and aspects of interest, such as naturalness and humane treatment.

Attitudes differed with socio-demographic characteristics and degree of concern. Women, younger participants and those who had spent longer in education 
demonstrated the highest levels of concern and had more negative attitudes towards modern production systems. They were also those who were most likely to WTP for WFP, supporting findings from a previous review investigating WTP (Clark et al. 2015). Women had more negative attitudes, voiced stronger concerns towards modern farming, and had the highest WTP. Women are generally assumed to be more caring, reflected in the social roles they tend to fulfil (Kendall et al. 2006), and this links to them being more motivated by welfare concerns, considering the issue more emotively than men, and seemingly tending to anthropomorphise animals more. Younger consumers were more aware of modern farming practices, perhaps due to greater access to information thanks to the internet and social media, with older consumers, perhaps more familiar with more traditional and extensive systems and more traditional media channels, which may evoke less concern and may not give as much attention to FAW issues. In relation to WTP, older consumers are also more likely to be retired and so may not have the financial resources to pay for the more expensive WFP. The difference in age was not explored in depth in any of the qualitative studies, and it would be useful to explore this further to gain more insight into attitudinal differences, especially given the aging population in developed and some developing countries.

Education was linked with greater concern for welfare, with those who have studied longest reporting greater awareness and concern for FAW. Those with more knowledge also reported greater concerns, although those with more familiarity, such as those having previously worked or visited a farm, living in a rural area or having regular contact with farmers, were less concerned with modern production. This would confirm the assumption that self-reported measures of knowledge overestimate knowledge, and that a large number of misconceptions exist surrounding animal production which are likely to affect attitudes. For the most part, attitudes are based on perceived farming practices, rather than facts and actual experiences, suggesting a difference between public perception and the reality of farming. It also highlights the benefit of farm visits in raising awareness of current practices and addressing some of the misconceptions that exist, and the need for future research to include more objective measures of knowledge to provide realistic insights into public understanding.

Previous studies have linked increased income to an increased WTP, but increased income is not necessarily linked with greater concern about FAW. It would appear that those with higher incomes have the means to express their attitudes through their purchasing behaviours, rather than having greater concerns or more negative attitudes, and this seems to be the case with $\mathrm{ABC} 1$ consumers being most likely to consume WFP. One study reports that those of a higher social status value the more advanced quality attributes of products more (Vermeulen and Bienabe 2010), therefore it may be that they gain more value from WFP, perhaps from association with additional product attributes.

Socio-demographic characteristics and their relation to attitudes and behaviour were primarily discussed in quantitative studies, with few qualitative studies discussing differences between participant characteristics and attitudes. It should be noted that a number of studies reporting no significant differences attributable to socio-economic factors. Although there has been some debate as to the role of 
traditional marketing segmentation characteristics in ethical purchase decisions (Diamantopoulos et al. 2003), clear differences and heterogeneous preferences were observed in the review, providing evidence that niche markets exist, with females, younger individuals and those with a higher education having more affective orientations (Serpell 2004). This has implications for farmers in terms of potential welfare improvements to make and for private welfare initiatives, ensuring that products can be differentiated accordingly, and also supports the use of marketbased solutions for improving welfare.

National and cultural variations in FAW attitudes were also observed and there were differences between countries in relation to a number of factors, with Scandinavian countries generally reporting higher levels of trust in regulatory systems, knowledge and awareness of farming practices and they were generally the least concerned. Kjærnes et al. (2007) highlight that differing institutional contexts play a role in defining consumer attitudes, and the review findings would seem to support this with Scandinavian countries having stricter welfare regulations (Bock and van Huik 2007). Europe and North America were the two most studied regions, with Asia and South America only having three studies between them, and it would seem pertinent to investigate attitudes in these countries. Not only are they large and important markets where animal product consumption is predicted to increase dramatically, but these regions are also where most animal production is likely to occur in the future (Fraser 2008). It was also interesting to note the lack of awareness concerning FAW in China, and it would be interesting to explore this further in terms of FAW legislation, and in relation to both internal and export markets.

\section{The Concept of Welfare}

Tuyttens et al. (2010) describe finding a universal definition of what constitutes good welfare that will satisfy all stakeholders as challenging, with broader, more generalised aspects likely to meet the expectations of the majority. Reflecting this, two core concepts emerged as central to good welfare for the public; naturalness and humane treatment. These themes are not new to the literature (Blokhuis et al. 2003). Naturalness was associated with more extensive production systems, (for example, sufficient space and outdoor access). It was also central to what was considered to contribute to animal health and wellbeing, both physically and psychologically, with the latter an increasingly discussed but more contested welfare aspect. This suggests that concern is moving away from the basic health and hygiene of animals, towards a more holistic approach to animal health incorporating both their biological needs and behavioural characteristics (Austin et al. 2005). This reflects the shift from FAW measures being based on purely scientific information in relation to basic health and functioning, moving towards the incorporation of criteria in relation to natural living and the animals' affective state (Lassen et al. 2006).

No studies specifically focused on production diseases, with only 21 of the 80 studies $(26.25 \%)$ referring to them or antibiotic use. In the majority of cases this was not mentioned or discussed in depth, simply referring to an absence of disease or an avoidance of antibiotics, unless treatment is required. Concerns relating to 
production diseases also linked to health and safety concerns by consumers. Production diseases, especially when related to the overuse of antibiotics, were an important part of the naturalness concept, and this was mainly in relation to prophylactic antibiotic use. At a time of increased concern about the scale of antibiotic use in farming (European Food Safety Authority 2015), increasing antibiotic resistance (Liu et al. 2015) and increased press attention and public concern over these (Soil Association 2015), it is pertinent to explore antibiotic use in intensive systems, as although consumers condone their use for treatment, they do not approve of prophylactic use, and this could have implications for future policy and product acceptability (in relation to both quality and safety).

Humane conditions were vital and housing conditions were strongly associated with this. Housing conditions were the most frequently discussed aspect of production, which is unsurprising due to increased legislation in these areas in particular in Europe (Fraser 2008). Concerns raised in relation to housing systems were primarily associated with outdoor access and space restrictions which were thought to adversely affect animal health and constrain natural behaviours and associated wellbeing. The latter ties in with the increasing recognition that animals are sentient beings, and therefore can experience emotion. There was also a growing recognition of "off the farm" welfare issues, such as transport and slaughter, and the need to make these as humane as possible.

Both of these central concepts pose an interesting challenge for intensive production, as contemporary farming systems inevitably breach one, or both, of these concepts in the trade-off between productivity and welfare. Although modern production delivers benefits which the public recognise, there is a need to demonstrate that both productivity and welfare need to be taken into consideration. Consumer and citizen expectations will also need to be managed in relation to what is and what is not feasible within these systems, with alternative extensive production systems being offered and promoted as acceptable alternatives. It is also relevant to examine naturalness and humane treatment in the context of both public and private benefits, and the extent to which various intensive production practices and interventions breach these.

\section{Citizen Versus Consumer Role}

Individuals may have different attitudes and behaviours depending on whether they are acting in their role as a citizen or a consumer. As citizens, they report a high level of concern about modern production systems, rating FAW, and having welfare friendly production systems, as important. However, as consumers they have other priorities when it comes to purchasing products. This is exemplified through the inconsistency between the large proportion reporting concern for welfare, and the much smaller proportion having either altered their consumption habits as a result of welfare concerns, or currently purchasing/WTP for WFP. The wider concern voiced by citizens and the existence of concerned consumers means that both legislative and market-based solutions are necessary for providing and establishing welfare standards. This ensures that concerns and attitudes of non-consumers are still 
considered, as in their role as citizens, they may participate in referendums and other pro-welfare behaviours aside from product consumption (Grunert 2006).

Throughout the analysis the theme of anthropocentric versus zoocentric motives was observed Consumer concerns were not solely motivated by ethical considerations and concern for animals, reflecting the affect versus utility orientation discussed by Serpell (2004). Perceived consumer benefits, such as healthier and safer products also motivated consumers to select WFP. Anthropocentric motivations also underpinned some of the subthemes in the analysis, such as the underlying naturalness concerns, concerns over production diseases and associations with additional product attributes. Health and safety concerns in particular were important, and this may reflect food safety incidents and disease epidemics involving animal production systems, such as BSE (Grunert et al. 2004).

Consumers appear ambivalent towards modern farming, being appreciative of the consistent, safe and affordable products it offers yet voicing a number of concerns about the systems producing it (Boogaard et al. 2011). One subgroup of consumers do not let their concerns affect their consumption of animal products, indicating that some use dissonance or coping strategies to enable animal product consumption with a clear conscience and reduced feelings of guilt (Ingenbleek and Immink 2011; Grunert 2006; Schipper et al. 2006). A sub-group of more concerned consumers were identified who are motivated by ethical concerns and have greater engagement in pro-welfare behaviours, such as being willing to or already have made changes to their diet, by reducing animal product consumption or through purchasing WFP. They appear to have the means to do this regularly and also appear to less price sensitive to WFP. These individuals have a much smaller gap between their attitudes and their behaviour, in this case their consumption practices and purchasing behaviour.

\section{Barriers and Facilitators to Consumption of Higher Welfare Products}

A number of barriers and facilitators to the consumption of WFP were identified. Different groups of consumers express different preferences for certain approaches to FAW (de Jonge and van Trijp 2013). Animal welfare was rarely a consideration whilst shopping, except for more involved consumers, with other intrinsic and extrinsic attributes receiving much higher prioritisation, such as health, safety, quality and sensory characteristics as previously reported in the literature (Frewer et al. 2005).

The availability of WFP was also a limiting factor in terms of consumers' ability to purchase FAW (Tawse 2010). The absence of understandable and appropriate labelling also contributed to consumer difficulties with consumers reporting either that they were unable to identify the production systems used from current labels, with many described as unclear, or their being too many labels being available which resulted in consumer confusion. Another criticism was the lack of credibility of current schemes, with consumers viewing them as a marketing strategy. Labels can only be effective if trust exists between consumers and those offering the guarantees associated with a particular product attribute, with this credibility essential for ensuring that displayed information is believed and used (Grunert 
2006; McInerney 2004). This could be achieved through certification from an independent body, which may reduce risks associated with purchase. However, labelling was the preferred mechanism for conveying information about production systems, providing a clear, consistent approach was taken. This is potentially important given the lack of knowledge consumers have in relation to farming (Ingenbleek and Immink 2011).

Consumers viewed WFP as more expensive and not affordable by all consumers. Minimum welfare standards should not therefore result in consumers being priced out of the market. This means either subsidies, or additional optional higher welfare schemes that take into account the aforementioned considerations; i.e. they are clear, have specific criteria, and are well monitored, are put in place so that additional costs of production are not passed onto consumers. Consumers reported mixed beliefs as to the implications of their food choices, with doubts being expressed regarding whether purchasing WFP actually improves animals' lives. As markets are largely consumer driven this supports Vanhonacker and Verbeke (2009) conclusions that consumers lack any real insight into the implications of their food purchasing behaviour on the supply chain, and further highlights the need for improved communication surrounding welfare. Potential facilitators to the consumption of WFP were identified, such as the importance attributed to it by the majority of citizens and the associations WFP have with additional product attributes. Although the importance attributed to FAW did not translate into altered consumption practices or the purchase of WFP, this suggests the need to both ensuring higher di minimus standards of welfare and markets for WFP.

Consumers associated higher welfare with other product attributes (Grunert 2006), especially other extrinsic product attributes such as safety, health and quality. For example, WFP were believed to use less or no antibiotics, therefore were thought to be both safer and of a higher quality. This also implies that a welfare friendly guarantee acts as an additional assurance of other relevant product attributes, which means any WTP valuations will also be a reflection of this, as consumers do not just perceive value from welfare alone (Bennett et al. 2002). Environmental attributes were also important for a number of participants in the studies, with higher welfare systems associated with environmental benefits, although this may not be the case in reality (Leinonen et al. 2012). Welfare is an important component of quality assessment, even if it is not motivated by concerns for FAW.

\section{Trust, Responsibility and Consequences for Communication}

All stakeholders were viewed as responsible for ensuring FAW in some way, implying tangible demonstration of how this is operationalised throughout the food chain. Communication and reassurances from all stakeholders regarding their commitment and procedures for ensuring welfare will provide greater transparency, and help develop greater trust, and the best ways of communicating need to be explored in the future. The government are viewed as largely responsible, mainly due to their influence and the ability to implement regulations and monitoring procedures to ensure acceptable minimum standards. Ensuring transparent 
legislation, with both clear and acceptable criteria is therefore important. Farmers were also viewed as responsible for FAW, which is unsurprising given they are directly involved in production. The challenges faced by farmers were acknowledged, as was the need for them to be able to make a living from production. Retailers were also mentioned as responsible for ensuring that they source appropriately produced products, and that their suppliers are adopt FAW practices. A number of retailers, keen to be seen as responsible, have already adopted welfare friendly positions (Waitrose 2015). Although the public were viewed as having a role in ensuring welfare friendly production, some had doubts over their impact due to their lack of direct involvement. This ties in with the aforementioned lack of perceived personal influence ("Barriers and Facilitators to Consumption of Higher Welfare Products" section).

Consumers expressed a requirement to be better informed about FAW, even in light of the dissonance reducing activities. Improved communication was emphasised throughout the food-chain. Involvement of all stakeholders will deliver a more balanced perspective on modern production. Central to communication should be the core concepts of naturalness and humane treatment, and consideration of public concerns should be incorporated into future agricultural policy (Blokhuis et al. 2003), as consumers can only act in accordance with their values if they are aware of the issues surrounding production in the first instance (Tawse 2010).

\section{Conclusion}

This study sought to explore consumer attitudes towards FAW. Attitudes towards modern farming were mostly negative, with women, younger individuals, those with a higher education and who are less familiar with modern production likely to me more concerned. Naturalness and humane treatment emerged as 2 core concepts of welfare and violation of these increased consumer concern for welfare and contributed towards more negative attitudes towards production systems. More welfare friendly systems were associated with additional benefits for the consumer; higher quality, safer and healthier products, and this is most likely linked to naturalness concern. Concerns associated with diseases originating production systems did not emerge as relevant, with the exception of the use of antibiotics, Despite the majority considering FAW conditions a concern, welfare was not a prioritisation when shopping, and a number of barriers to consumption were raised, such as price, availability and perceived personal influence. A number of dissonance strategies were also adopted to enable consumers to maintain their current consumption practices with a clear conscience, and improved communication from stakeholders along the food chain was identified.

Acknowledgments This project has received funding from the European Union's Seventh Framework Programme for research, technological development and demonstration under Grant Agreement No. 613574.

\section{Compliance with ethical standards}


Conflict of interest The authors declare that they have no conflict of interest.

Open Access This article is distributed under the terms of the Creative Commons Attribution 4.0 International License (http://creativecommons.org/licenses/by/4.0/), which permits unrestricted use, distribution, and reproduction in any medium, provided you give appropriate credit to the original author(s) and the source, provide a link to the Creative Commons license, and indicate if changes were made.

\section{References}

Austin, E. J., Deary, I. J., Edwards-Jones, G., \& Arey, D. (2005). Attitudes to farm animal welfare: Factor structure and personality correlates in farmers and agriculture student. Journal of Individual Differences, 26(3), 107-120.

Bengtsson, B., \& Greko, C. (2014). Antibiotic resistance-consequences for animal health, welfare, and food production. Upsala Journal of Medical Sciences, 119(2), 96-102.

Bennett, R. M., Anderson, J., \& Blaney, R. J. P. (2002). Moral intensity and willingness to pay concerning farm animal welfare issues and the implications for agricultural policy. Journal of Agricultural and Environmental Ethics, 15(2), 187-202.

Bennett, R. M., \& Blaney, R. J. P. (2003). Estimating the benefits of farm animal welfare legislation using the contingent valuation method. Agricultural Economics, 29(1), 85-98.

Bennett, R., Kehlbacher, A., \& Balcombe, K. (2012). A method for the economic valuation of animal welfare benefits using a single welfare score. Animal Welfare, 21(SUPPL. 1), 125-130.

Blokhuis, H. J., Jones, R. B., Geers, R., Miele, M., \& Veissier, I. (2003). Measuring and monitoring animal welfare: Transparency in the food product quality chain. Animal Welfare, 12(4), 445-455.

Bock, B. B., \& van Huik, M. M. (2007). Animal welfare: The attitudes and behaviour of European pig farmers. British Food Journal, 109(11), 931-944.

Boogaard, B. K., Bock, B. B., Oosting, S. J., Wiskerke, J. S. C., \& van der Zijpp, A. J. (2011). Social acceptance of dairy farming: The ambivalence between the two faces of modernity. Journal of Agricultural and Environmental Ethics, 24(3), 259-282.

Boogaard, B. K., Oosting, S. J., \& Bock, B. B. (2006). Elements of societal perception of farm animal welfare: A quantitative study in The Netherlands. Livestock Science, 104(1-2), 13-22.

Braun, V., \& Clarke, V. (2006). Using thematic analysis in psychology. Qualitative Research in Psychology, 3, 77-101.

Bryman, A. (2012). Social research methods. Oxford: Oxford University Press.

Clark, B., Stewart, G. B., Panzone, L. A., \& Frewer, L. J. (2014) A protocol for a systematic review into consumers' attitudes, beliefs and perceived ethical obligations towards farm animal welfare. PeerJ PrePrints 2 [PrePrint]. https://peerj.com/preprints/676/. Accessed Dec 12, 2014.

de Jonge, J., \& van Trijp, H. C. M. (2013). The impact of broiler production system practices on consumer perceptions of animal welfare. Poultry Science, 92(12), 3080-3095.

Diamantopoulos, A., Schlegelmilch, B. B., Sinkovics, R. R., \& Bohlen, G. M. (2003). Can sociodemographics still play a role in profiling green consumers? A review of the evidence and an empirical investigation. Journal of Business Research, 56(6), 465-480.

Ellis, K. A., Billington, K., McNeil, B., \& McKeegan, D. E. F. (2009). Public opinion on UK milk marketing and dairy cow welfare. Animal Welfare, 18(3), 267-282.

European Commission. (2007). Attitudes of EU citizens towards animal welfare. Special Eurobarometer 270. Wave 66.1.TNS Opinion and Social. IR. http://ec.europa.eu/public_opinion/archives/ebs/ebs_ 270_en.pdf. Accessed Oct 20, 2014.

European Food Safety Authority. (2015). ECDC/EFSA/EMA first joint report on the integrated analysis of the consumption of antimicrobial agents and occurrence of antimicrobial resistance in bacteria from humans and food-producing animals. EFSA Journal. doi:10.2903/j.efsa.2015.4006.

Fraser, D. (2008). Towards a global perspective on farm animal welfare. Applied Animal Behaviour Science, 113(4), 330-339.

Frewer, L. J., Kole, A., Van De Kroon, S. M. A., \& De Lauwere, C. (2005). Consumer attitudes towards the development of animal-friendly husbandry systems. Journal of Agricultural and Environmental Ethics, 18(4), 345-367. 
Godfray, H. C. J., \& Garnett, T. (2014). Food security and sustainable intensification. Philosophical Transactions of the Royal Society, 369, 20120273.

Grunert, K. G. (2006). Future trends and consumer lifestyles with regard to meat consumption. Meat Science, 74(1), 149-160.

Grunert, K. G., Bredahl, L., \& Brunsø, K. (2004). Consumer perception of meat quality and implications for product development in the meat sector-A review. Meat Science, 66(2), 259-272.

Harper, G., \& Henson, S. (2001). Consumer concerns about animal welfare and the impact on food choice, Final Report. EU FAIR CT98-3678. Centre for Food Economics Research, The University of Reading.

Hughes, P., \& Heritage, J. (2002). Antibiotics as animal growth promoters. http://www.fao.org/docrep/ article/agrippa/555_en.htm. Accessed July 3, 2015.

Ingenbleek, P. T. M., \& Immink, V. M. (2011). Consumer decision-making for animal-friendly products: Synthesis and implications. Animal Welfare, 20(1), 11-19.

Jensen, H. H. (2006). Consumer issues and demand. http://www.choicesmagazine.org/2006-3/animal/ 2006-3-09.htm. Accessed June 12, 2015.

Kendall, H. A., Lobao, L. M., \& Sharp, J. S. (2006). Public concern with animal well-being: place. Social Structural Location, and Individual Experience, Rural Sociology, 71(3), 399-428.

Kjærnes, U., Miele, M., \& Roex, J. (2007). Attitudes of consumers, retailers and producers to farm animal welfare. Welfare Quality Reports no. 2. Cardiff: Cardiff University, School of City and Regional Planning.

Lagerkvist, C. J., \& Hess, S. (2011). A meta-analysis of consumer willingness to pay for farm animal welfare. European Review of Agricultural Economics, 38(1), 55-78.

Lassen, J., Sandøe, P., \& Forkman, B. (2006). Happy pigs are dirty!-Conflicting perspectives on animal welfare. Livestock Science, 103(3), 221-230.

Leinonen, I., Williams, A. G., Wiseman, J., Guy, J., \& Kyriazakis, I. (2012). Predicting the environmental impacts of chicken systems in the United Kingdom through a life cycle assessment: Broiler production systems. Poultry Science, 91(1), 8-25.

Liu et al. (2015). Emergence of plasmid-mediated colistin resistance mechanism MCR-1 in animals and human beings in China: A microbiological and molecular biological study. The Lancet, 16(2), $161-168$.

Lu, Y. (2013). Consumer preference for eggs from enhanced animal welfare production system: A stated choice analysis. PhD Thesis, University of Guelph.

Makdisi, F., \& Marggraf, R. (2011). Consumer willingness to pay for farm animal welfare in GermanyThe case of broiler chickens. Vortrag anlässlich der 51. Jahrestagung der GEWISOLA, Unternehmerische Landwirtschaft zwischen Marktanforderungen und gesellschaftlichen Erwartungen, Halle, Germany, 30th September.

McInerney, J. (2004). Animal welfare, economics and policy: Report on a study undertaken for the farm \& animal health economics. London: Department of Environment, Food and Rural Affairs.

McKendree, M. G. S., Croney, C. C., \& Widmar, N. J. O. (2014). Effects of demographic factors and information sources on United States consumer perceptions of animal welfare. Journal of Animal Science, 92(7), 3161-3173.

Meader, N., King, K., Llewellyn, A., Norman, G., Brown, J., Rodgers, M., et al. (2014). A checklist designed to aid consistency and reproducibility of GRADE assessments: Development and pilot validation. Systematic Reviews, 3(1), 1-9.

Moran, D., \& McVittie, A. (2008). Estimation of the value the public places on regulations to improve broiler welfare. Animal Welfare, 17(1), 43-52.

Popay, J., Roberts, H., Sowden, A., Petticrew, M., Arai, L., Rodgers, M., Britten, N., Roen, K., \& Duffy, S. (2006). Guidance on the conduct of narrative synthesis in systematic reviews. A product from the ESRC methods programme. Version, 1.

Schipper, L., Torjusen, H., Beekman, V., Terragni, L., \& Korthals, M. (2006). All animals are equal but some animals are more equal than others: A cross-cultural comparison of human-animal relationships in Netherlands and Norway. In M. Kaiser \& M. Lien (Eds.), Ethics and the politics of food (pp. 535-539). Wageningen: Wageningen Academic Publishers.

Schröder, M. J. A., \& McEachern, M. G. (2004). Consumer value conflicts surrounding ethical food purchase decisions: A focus on animal welfare. International Journal of Consumer Studies, 28(2), $168-177$.

Serpell, J. A. (2004). Factors influencing human attitudes to animals and their welfare. Animal Welfare, 13(Supplement 1), 145-151. 
Sniehotta, F. F., Presseau, J., \& Araújo-Soares, V. (2014). Time to retire the theory of planned behaviour. Health Psychology Review, 8(1), 1-7.

Soil Association. (2015). Antibiotic resistance: A looming crisis. http://www.soilassociation.org/ antibiotics. Accessed: Nov 21, 2015.

Stewart, G. B., Higgins, J. P., Schünemann, H., \& Meader, N. (2015). The use of bayesian networks to assess the quality of evidence from research synthesis: 1. PLOS ONE, 10(4), e0114497.

Tawse, J. (2010). Consumer attitudes towards farm animals and their welfare: A pig production case study. Bioscience Horizons, 3(2), 156-165.

te Velde, H., Aarts, N., \& Van Woerkum, C. (2002). Dealing with ambivalence: Farmers' and consumers' perceptions of animal welfare in livestock breeding. Journal of Agricultural and Environmental Ethics, 15(2), 203-219.

Thomas, J., \& Harden, A. (2008). Methods for the thematic synthesis of qualitative research in systematic reviews. BMC Medical Research Methodology, 8(1), 45-55.

Tuyttens, F. A. M., Vanhonacker, F., Van Poucke, E., \& Verbeke, W. (2010). Quantitative verification of the correspondence between the Welfare Quality ${ }^{\circledR}$ operational definition of farm animal welfare and the opinion of Flemish farmers, citizens and vegetarians. Livestock Science, 131(1), 108-114.

Vanhonacker, F., \& Verbeke, W. (2009). Buying higher welfare poultry products? Profiling Flemish consumers who do and do not, Poultry Science, 88(12), 2702-2711.

Vermeulen, H., \& Bienabe, E. (2010). The quality turn in South Africa: Insights from a comprehensive investigation into the food quality behaviours, perceptions and knowledge of South African consumers with a focus on middle and upper socioeconomic groups. In AAAE third conferencel AEASA 48th conference. Cape Town, South Africa, September 19-23. African Association of Agricultural Economists (AAAE) \& Agricultural Economics Association of South Africa (AEASA).

Waitrose. (2015). Animal welfare at Waitrose. http://www.waitrose.com/home/inspiration/about_ waitrose/the_waitrose_way/waitrose_animal_welfarecommitments.html. Accessed Nov 25, 2015.

Wathes, C. M., Buller, H., Maggs, H., \& Campbell, M. L. (2013). Livestock production in the UK in the 21st century: A perfect storm averted? Animals, 3(3), 574-583.

Weitzman, S. (2000). Software and qualitative research. In N. K. Denzin \& Y. S. Lincoln (Eds.), Handbook of qualitative research. London: Sage.

Yin, R. K. (2009). Case study research: Design and methods (4th ed.). London: Sage. 